\title{
IS BITCOIN BECOMING AN ALTERNATIVE INVESTMENT OPTION FOR TURKEY? A COMPARATIVE ECONOMETRIC INVESTIGATION OF THE INTERACTION BETWEEN CRYPTO CURRENCIES
}

DOI: 10.17261/Pressacademia.2019.1022

RJBM- V.6-ISS.1-2019(6)-p.68-78

\section{Mustafa Ozyesil}

Istanbul Aydin University, Anadolubil Vocational School, Business Management, Istanbul, Turkey. mozyesil@aydin.edu.tr, ORCID: 0000-0002-4442-7087

Date Received: January 19, 2019

Date Accepted: March 22, 2019

To cite this document

Ozyesil, M. (2019). Is Bitcoin becoming an alternative investment option for Turkey? A comparative econometric investigation of the interaction between crypto currencies. Research Journal of Business and Management (RJBM), V.6(1), p.68-78.

Permemant link to this document: http://doi.org/10.17261/Pressacademia.2019.1022

Copyright: Published by PressAcademia and limited licenced re-use rights only.

\begin{abstract}
Purpose- The main objective of this study is to examine the mutual interaction between crypto money (coins) types. For this purpose, we investigated the sensitivity existence of any crypto money to changes in other crypto types.

Methodology- In this study, to find out whether the interaction (relationship) exists between cryptocurrencies VAR model will be used through daily closing prices of each crypt money. Under the VAR analysis, variance decomposition, impact-response functions analysis will be done and finally, Granger Causality Test will be performed.

Findings- According to the results of VAR analysis based on Variance Decomposition, BITCOIN, BT CASH and Tether are largely external variables and their prices are not significantly affected by other crypto currencies. In contrast, the values of Etherum, Lite Coin and QTUM are significantly affected by the changes in the values of other crypto coins.

Conclusion- In accordance with findings obtained from analysis, we observed that Tether is moving towards becoming an alternative investment tool for all the crypto moneys. Other crypto coins tend to move in the same direction.
\end{abstract}

Keywords: Crypto currency, bitcoin, unit root test, VAR model, variance decomposition, impact-response functions. JEL Codes: C23, C58, G10, G32

\section{INTRODUCTION}

Money has been known as conventional paper money which is issued by the governments and physically circulated. Crypto currencies are digital alternatives for the classical money concept. Crypto currencies are the outputs of the some technological advancements that lower the cost of processing electronic payments (Luther, 2015:553). Currently they are used for the purpose of implementing payments that is substantial reason for introduced first and for the trading speculation (Elbahraway et.al. 2017:2). Another reason for making crypto currencies are so popular is intensively growing concern about exchange rates like USD and EUR that they will become less valuable in the future because of inflation, devaluation and government interference etc. (Luther, 2015:553). As a result crypto currencies are gaining more popularity. Crpypto currencies have some appealing benefits for the users as follow (Cocco et.al, 2017:345):

- Decentralization. It doesn't rest on central bank or government to regulate.

- Quasi- anonymous transactions. It offers more anonymity than traditional electronic payments.

- Money supply limitation. Anyone can not issue more than their limits that protects economic units from inflation problem.

- Finally their transaction are irreversible.

After the Bitcoin grabbed the attention of finance environment by high price fluctuations remarkably resulted in intensively increasing of awareness of the Cryptocurrency term and lots of other cryptocurrencies were issued by the companies or even by the governments. Currently many crypto money types ( 2.524 crypto moneys) are being traded and their total daily transaction volume as of March 2019 is around 35 Billion USD. Therefore, in the study we wanted to analyze movement of 
selected cryptocurrencies and detect any relationship occurred among them. Through this paper, we searched which kind of cryptocurrency is becoming a substitution for the other ones through the analyzing interaction between them.

\section{DATA AND METHODOLOGY}

\subsection{Data Structure}

In this study as cryptocurrencies; Bitcoin (BIT), Tether (TET), Etherum (ETH), Lite Coin (LIT), BT (BT) Cash, QTUM (QTM) were used. We conducted analysis based on the daily data of 27.10.2017-25.02.2019 period. Since the time series of the each crypto money is different, we matched data range for all crypto money included in the sample. To reduce risk of the heteroscedasticity problem all series were used after taking their natural logarithms. Thus we are able to interpret the evident thanks to obtaining flexibility coefficient. The origin of the data is www.investing.com.

\subsection{Method}

For the purpose of avoiding spurious regression issue, we first tested the stationary degree of the series through the ADF (Augmented Dickey Fuller) and PP (Phillips Perron) unit root tests. We performed Impulse-Response Function and Variance Decomposition methods based on the VAR (Vector Aotoregressive) method and the Granger Causality Test to observe interactions between the series.

\section{ANALYSIS AND FINDINGS}

\subsection{Unit Root Test}

To initiate subsequent analyzes and acquire trustable and reliable test results, the first thing that it should be done is determining the stationary level of the series (Cochrane, 1991). Unless we work on stationary data, it will not be possible to produce significant results to make estimation. Therefore unit root tests are being used in econometric analysis to find out stationary of series. We analyzed the stationary level of the series via the ADF and PP unit root tests. There are many unit root test alternatives. ADF is taken into account because it is generally used by majority of the researchers and PP provides stronger outcomes than ADF (Arltova ve Fedorová, 2016) in the trend analysis. These are the reason of choosing these type of unit root tests.

The hypotheses for these tests are the same and can be established as follows:

$H_{0}$ : Series are not stationary.

$H_{1}$ : Series are stationary.

In the literature, when the series that is tested by the unit root test become stationary based on their origin values named $I(0)$ but if they get stationary after calculating their first difference named as I(1) (Dikmen, 2012: 304).

According to ADF and PP unit root tests the obtained results are presented in the Table 1.

Table 1: Unit Root Test Results

\begin{tabular}{|c|c|c|c|c|c|}
\hline \multirow[b]{2}{*}{ Variable } & \multicolumn{2}{|c|}{ Origin Level } & \multicolumn{2}{|c|}{ First Difference } & \multirow[b]{2}{*}{ Decision } \\
\hline & $\begin{array}{l}\text { Probability Value } \\
\text { of the ADF Test }\end{array}$ & $\begin{array}{c}\text { Probability Value } \\
\text { of the PP Test }\end{array}$ & $\begin{array}{c}\text { Probability Value } \\
\text { of the ADF Test }\end{array}$ & $\begin{array}{c}\text { Probability Value } \\
\text { of the PP Test }\end{array}$ & \\
\hline LnBIT & 0.48 & 0.42 & $0.00 * * *$ & $0.00 * * *$ & $\mathrm{I}(1)$ \\
\hline LnBT & 0.45 & 0.43 & $0.00 * * *$ & $0.00 * * *$ & $\mathrm{I}(1)$ \\
\hline LnETH & 0.61 & 0.59 & $0.00 * * *$ & $0.00 * * *$ & $\mathrm{I}(1)$ \\
\hline LnLIT & 0.65 & 0.61 & $0.00 * * *$ & $0.00 * * *$ & $\mathrm{I}(1)$ \\
\hline LnQTM & 0.55 & 0.58 & $0.00 * * *$ & $0.00 * * *$ & $\mathrm{I}(1)$ \\
\hline LnTET & $0.01 * *$ & $0.00 * * *$ & - & - & $\mathrm{I}(0)$ \\
\hline
\end{tabular}

Note: The optimum lag length in the ADF test is determined according to the Akaike Criterion and the optimum bandwidth in the PP test is determined according to the Newey-West method. Since the PP test is considered to be more robust, the decision is finalized based on the results of the PP test when different results are produced by the ADF and PP test methods. ${ }^{* * *}$ and ${ }^{*}$ state that the related series is stationary at $1 \%$ and $10 \%$ significance level, respectively. The unit root tests were not performed for the series which were stationary in the origin level values.

According to Table 1, it can said that 5 series are determined as stationary at the first difference and remaining one is stationary at the origin level. VAR analysis can be conducted only based on the stationary series. Therefore we need to make all series used in the analyzes stationary. As a result the non-stationary series were converted to stationary form by taking their first difference. Even this result is enough to conclude that crypto moneys are still too volatile and they have not stabilized yet. 
To prevent mismatch problem in the sample, we calculated first differences of all series and then started to work on Var Model. Because there may emerge mismatch problem because of considering some series with their first difference values but using remaining one (LnTET) rest on origin value.

\section{VAR ANALYSIS}

In this study we decided to use Var Analysis developed by the Sims (1980) because it detects interactions between variables simultaneously (Trenca and Mutu, 2011: 33-37). Particularly in financial instruments, when the series move simultaneously, Var model will be more effective to find out relationship between the determinant factors (Triacca, 2017). Relationship between any two variables such as $Y$ and $X$ can be analyzed through the VAR model, by the following simultaneous equation system is used:

$$
\begin{aligned}
& Y_{t}=\alpha_{0}+\sum_{i=1}^{m} \alpha_{i} Y_{t-i}+\sum_{i=1}^{m} \beta_{i} X_{t-i}+u_{t} \\
& X_{t}=\gamma_{0}+\sum_{i=1}^{m} \gamma_{i} X_{t-i}+\sum_{i=1}^{m} \varphi_{i} Y_{t-i}+\vartheta_{t}
\end{aligned}
$$

In the formula, $\mathrm{m}$ refers the optimal delay length. In this study, VAR estimates were made for Equation 1 and Equation 2 separately. We first determined optimal delay length and the related results are listed in Appendix 1. Because of nature of the VAR analysis, the interpretations of the findings are made via the Impact-Response Functions and Variance Decomposition test results.

\subsection{Impact-Response Functions}

This model analyzes responses of any variables included in the VAR model to changes (shocks) occurred both in them and in other variables. In this type of analysis, response that is originated from series itself or from other series to a standarderror shock occurred in any variable will be examined (Rossi, 2011). In the study, generalized shocks are given while creating effect-response functions.

As it can be seen below; there several graphs so it will be suitable to explain order of the graph as what they mean. First graph in each group shows that any variable's response to the unexpected shock and to decide whether this shock causes decreasing or increasing effect. In the remaining graphs, the responses of the other variables to the shocks that come to the first variable are observed.

The results are shown below as follows:

\section{Chart 1: The Reaction of Other Cryptocurrencies to a Reducing Shock in BITCOIN's Price}

Response to Generalized One S.D. Innov ations \pm 2 S. E.

Response of DLNBIT to DLNBIT

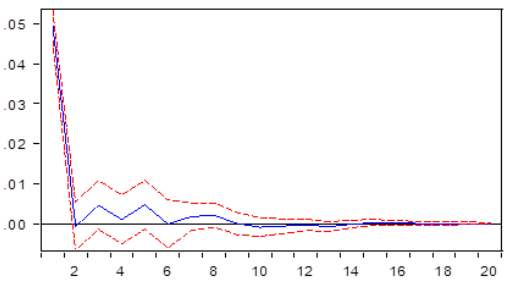

Response of DLNTET to DLNBIT

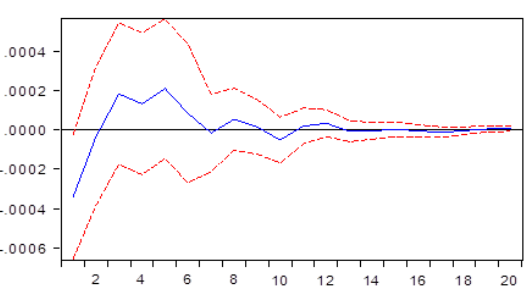

Response of DLNBT to DLNBIT

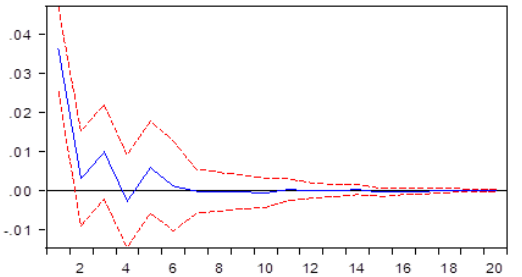

Response of DLNLIT to DLNBIT

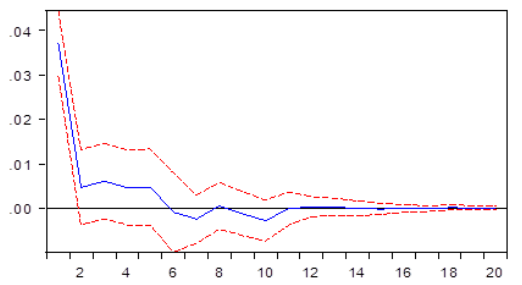

Response of DLNETH to DLNBIT

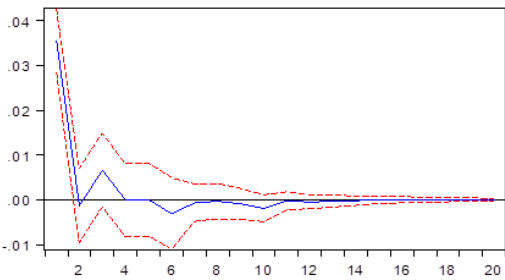

Response of DLNQTM to DLNBIT

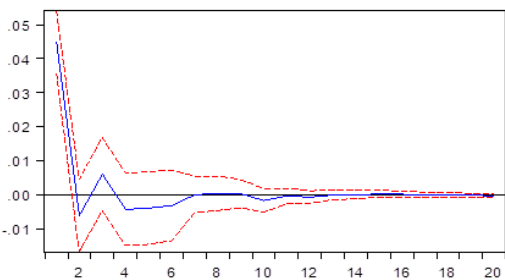


According to results represented in the graphs, it can be understood that BT CASH, Etherum, Lite Coin and QTUM respond in reducing way and Tether responds in increasing way to reducing shock occurred in Bitcoin's Prices. In this case, BITCOIN and Tether can be expressed as substitution cryptocurrencies. Shocks have lost their effect on average in 12 days.

\section{Chart 2: The Reaction of Other Cryptocurrencies and Exchange Rates to a Reducing Shock in BT CASH 's Price}

Response of DLNBT to DLNBT

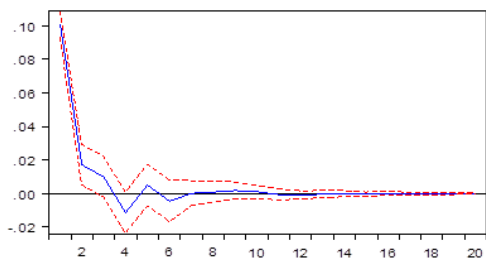

Response of DLNTET to DLNBT

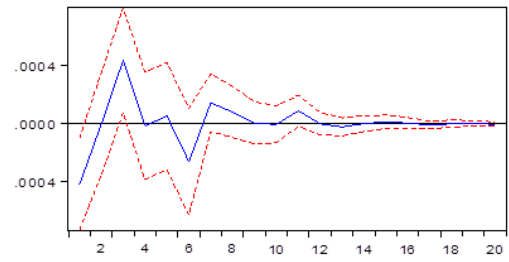

Response to General ized One S.D. Innov ations \pm 2 S.E.

Response of DLNBIT to DLNBT

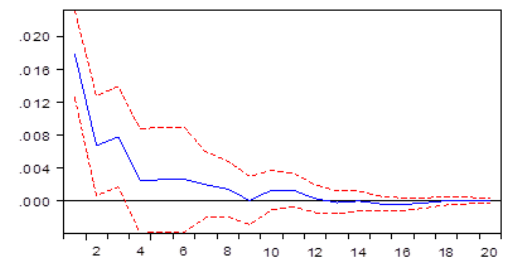

Response of DLNLIT to DLNBT

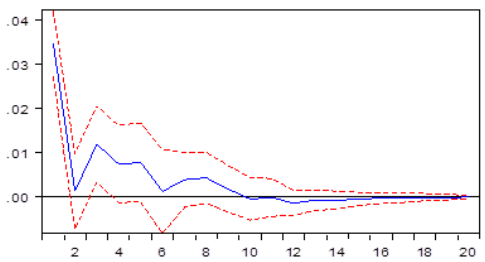

Response of DLNETH to DLNBT

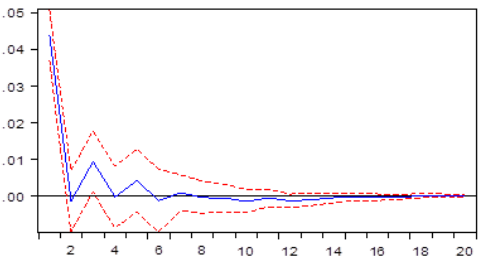

Response of DLN QTM to DLNBT

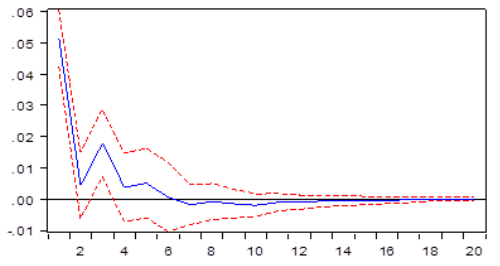

According to results represented in the graphs, it can be find out that BITCOIN, Etherum, Lite Coin and QTUM respond in reducing way and Tether responds in increasing way to reducing shock occurred in BT CASH 's Prices. In this case, BT CASH and Tether can be expressed as substitution cryptocurrencies. Shocks have lost their effect on average in 10 days.

\section{Chart 3: The Reaction of Other Cryptocurrencies and Exchange Rates to a Reducing Shock in Etherum's Price}

Response to Generalized One S.D. Innov ations \pm 2 S.E.

Response of DLNETH to DLNETH

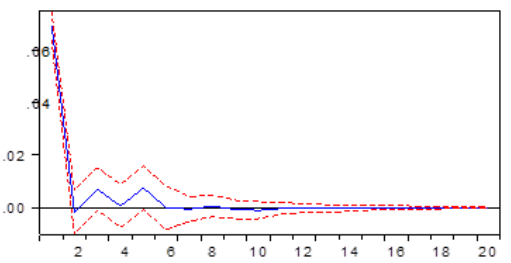

Res ponse of DLNTET to DLNETH

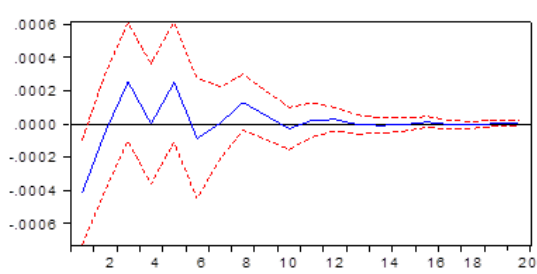

Response of DLNBIT to DLNETH

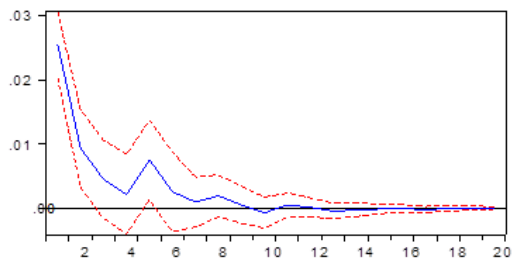

Response of DLNUT to DLNETH

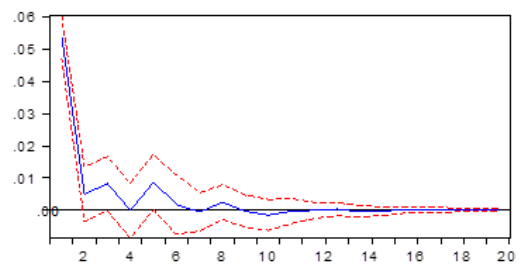

Response of DLNBT to DLNETH

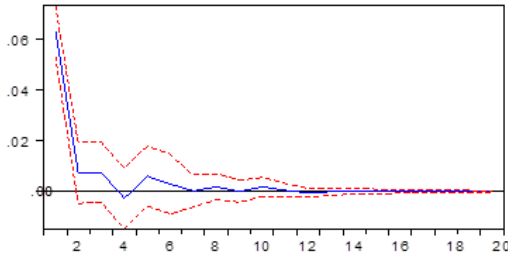

Response of DLNQTM to DLNETH

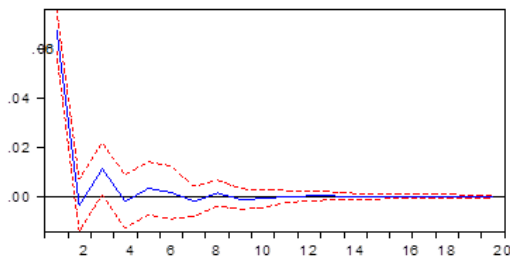

According to results represented in the graphs, it can be observed that BITCOIN, BT CASH, Lite Coin and QTUM respond in reducing way and Tether responds in increasing way to reducing shock occurred in Etherum 's Prices. In this case, Etherum and Tether can be expressed as substitution cryptocurrencies. Shocks have lost their effect on average in 10 days. 


\section{Chart 4: The Reaction of Other Cryptocurrencies and Exchange Rates to a Reducing Shock in Lite Coin's Price}

Response to Generalized One S.D. Innov ations \pm 2 S.E

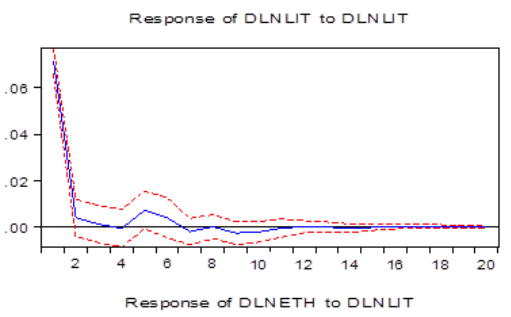

Response of DLNBIT to DLNUT

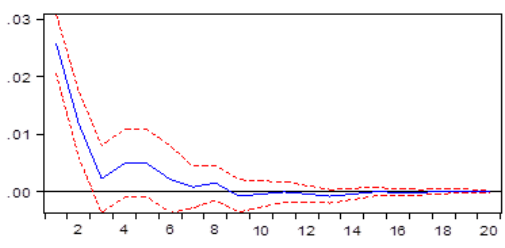

Response of DLN TET to DLN UT
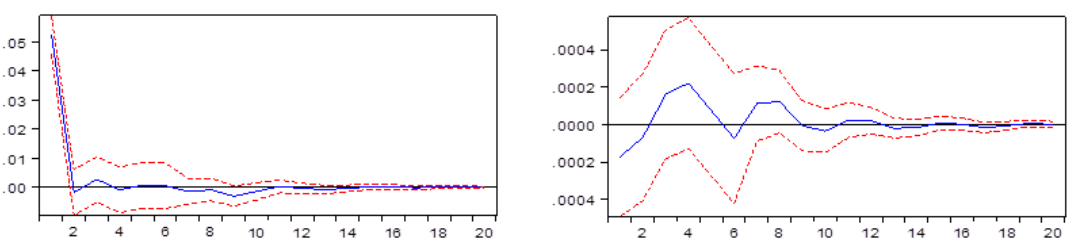

Response of DLN BT to DLNLIT

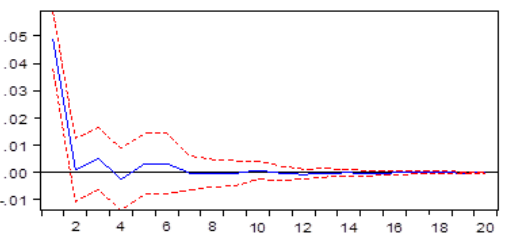

Response of DLNQTM to DLNLIT

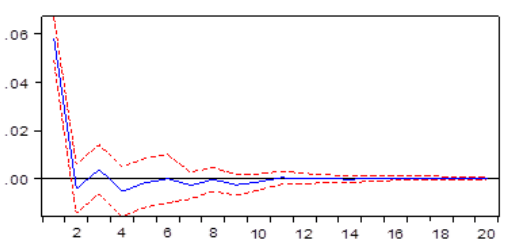

According to these graphs, it can be found that BITCOIN, BT CASH, Lite Coin and QTUM respond in reducing way and Tether responds in increasing way to reducing shock occurred in Lite Coin's Prices. In this case, Lite Coin's and Tether can be expressed as substitution cryptocurrencies. Shocks have lost their effect on average in 12 days.

\section{Chart 6: The Reaction of Other Cryptocurrencies and Exchange Rates to a Reducing Shock in QTUM 's Price}

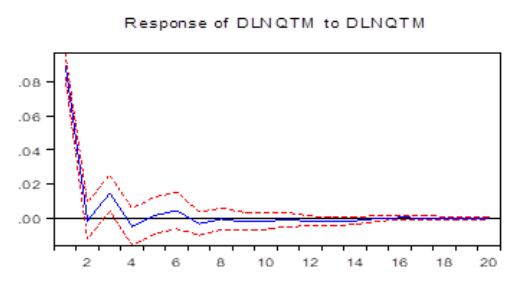

Response of DLNETH to DLNOTM

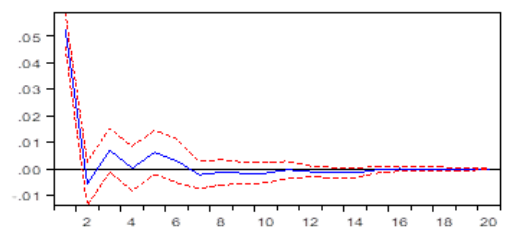

Response to Generalized One S.D. Innovations \pm 2 S.E. Response of DLNBIT to DLNQTM

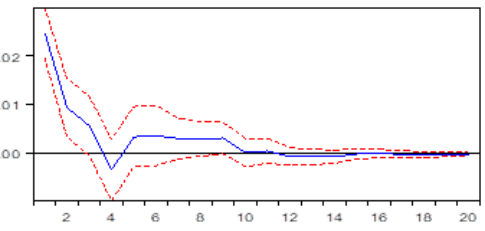

Response of DLNLIT to DLNQTM

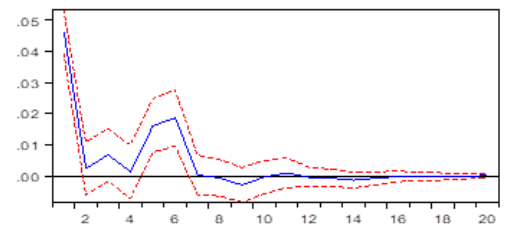

Response of DLNBT to DLNOTM

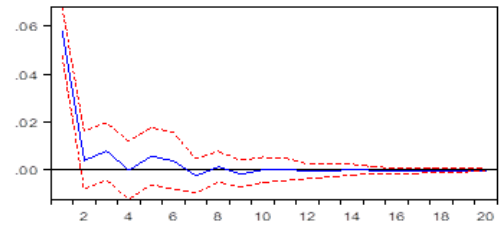

Response of DLNTET to DLNOTM

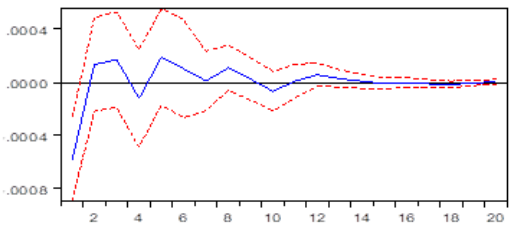

According to these graphs, it can be found that BITCOIN, BT CASH, Etherum and Lit Coin respond in reducing way and Tether respond in increasing way to reducing shock occurred in QTUM's Prices. In this case, QTUM and Tether can be expressed as substitution cryptocurrencies. Shocks have lost their effect on average in 14 days. 


\section{Chart 7: The Reaction of Other Cryptocurrencies and Exchange Rates to a Reducing Shock in Tether's Price}

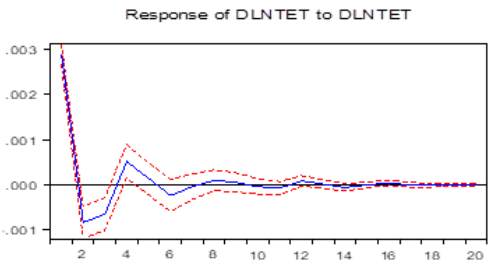

Response to Generalized One S.D. Innov ations \pm 2 S.E.

Response of DLNBIT to DLNTET

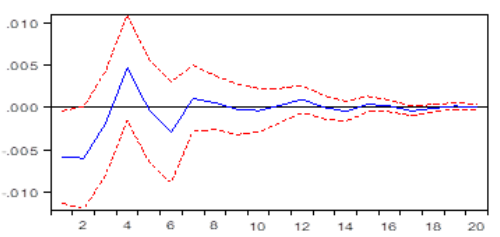

Response of DLNLT to DLNTET

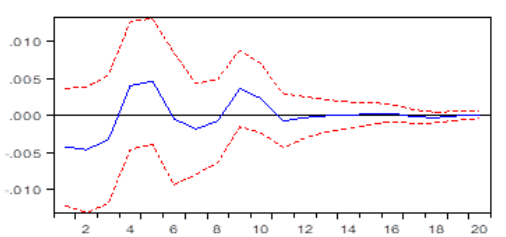

Response of DLNBT to DLNTET

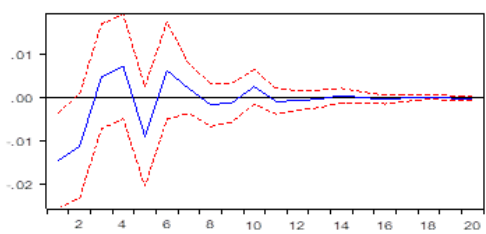

Response of DLNQTM to DLNTET

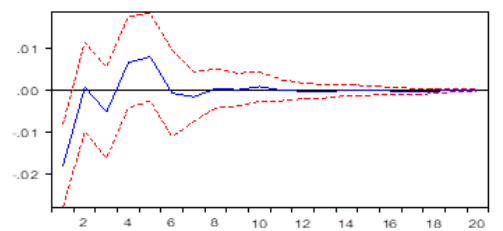

According to these graphs, it can be found that all cryptocurrencies respond in increasing way to reducing shock occurred in Tether 's Prices. In this case, other cryptocurrencies and exchange rates and Tether can be expressed as substitution cryptocurrencies. Shocks have lost their effect on average in 14 days.

When the findings calculated from the impact-response functions are reviewed together, it can be claimed that Tether is gradually becoming an alternative investment tool for all crypto money types included in the sample. On the other hand, other cryptocurrencies tend to move in the same direction.

\subsection{Variance Decomposition}

Variance decomposition method is useful to decide how much of the change in each variable generated from changes in other variables and generated from itself (Tarl, 2012: 469). In the variance decomposition, the values in the first period in which the distribution reaches equilibrium are interpreted. In this study, variance decomposition was made for each variable separately and the findings are presented in the tables below. The variable which is tried to be explained in each table is shown as bold and the data shows how much of the changes in this variable are caused by itself. Other columns refer to the effects of changes in other variables in the analysis on the variable to be explained.

Table 2: Results of Variance Decomposition for Determining the Causes of Changes in BITCOIN

\begin{tabular}{ccccccc}
\hline \hline Period & DLNBIT & DLNBT & DLNETH & DLNLIT & DLNQTM & DLNTET \\
\hline \hline 1 & 100 & 0 & 0 & 0 & 0 & 0 \\
2 & 90.67 & 2.03 & 2.80 & 2.96 & 0.45 & 1.06 \\
3 & 88.65 & 3.49 & 2.78 & 3.07 & 0.59 & 1.03 \\
4 & 83.69 & 3.45 & 2.65 & 3.71 & 3.11 & 1.43 \\
5 & 82.20 & 3.39 & 4.01 & 3.68 & 3.34 & 1.39 \\
6 & 80.72 & 3.58 & 4.05 & 3.63 & 3.50 & 1.55 \\
7 & 80.18 & 3.61 & 4.03 & 3.61 & 3.78 & 1.65 \\
$\mathbf{8}$ & $\mathbf{7 9 . 9 6}$ & $\mathbf{3 . 6 1}$ & $\mathbf{4 . 0 3}$ & $\mathbf{3 . 5 9}$ & $\mathbf{3 . 9 1}$ & $\mathbf{1 . 7 0}$ \\
9 & 79.27 & 3.58 & 4.02 & 3.66 & 4.60 & 1.70 \\
\hline \hline
\end{tabular}

According to Table 2, after 8th period, in the distribution, equilibrium was established. In this case, $79.96 \%$ of the changes in BITCOIN were caused by itself and 3.61\% from BT CASH, $4.03 \%$ from Etherum, 3.59\% from Lite Coin, 3.91\% of the QTUM and 1.7\% from Tether. Cryptocurrencies that affect Bitcoin most except for itself are Etherum, QTUM, BT CASH and Lite Coin respectively. 
Table 3: Results of Variance Decomposition for Determining the Causes of Changes in BT CASH

\begin{tabular}{ccccccc}
\hline \hline Period & DLNBIT & DLNBT & DLNETH & DLNLIT & DLNQTM & DLNTET \\
\hline \hline 1 & 12.87 & 87.13 & 0 & 0 & 0 & 0 \\
2 & 12.37 & 85.91 & 0.11 & 0.45 & 0.16 & 0.81 \\
3 & 13.01 & 84.58 & 0.12 & 0.50 & 0.18 & 1.31 \\
4 & 12.73 & 83.49 & 0.40 & 0.49 & 0.47 & 1.72 \\
5 & 12.90 & 82.69 & 0.43 & 0.56 & 0.49 & 2.22 \\
$\mathbf{6}$ & $\mathbf{1 2 . 7 5}$ & $\mathbf{8 1 . 9 1}$ & $\mathbf{0 . 8 1}$ & $\mathbf{0 . 5 9}$ & $\mathbf{0 . 6 1}$ & $\mathbf{2 . 5 8}$ \\
7 & 12.73 & 81.73 & 0.81 & 0.59 & 0.74 & 2.61 \\
\hline \hline
\end{tabular}

According to Table 3, after 6th period, in the distribution, equilibrium was established. In this case, $81.91 \%$ of the changes in BT CASH were caused by itself and $12.75 \%$ from BITCOIN, $0.81 \%$ from Etherum, $0.59 \%$ from Lite Coin, $0.61 \%$ of the QTUM and $2.58 \%$ from Tether. Cryptocurrencies that affect BT CASH most except for itself are BITCOIN and Tether respectively.

Table 4: Results of Variance Decomposition for Determining the Causes of Changes in Etherum

\begin{tabular}{ccccccc}
\hline Period & DLNBIT & DLNBT & DLNETH & DLNLIT & DLNQTM & DLNTET \\
\hline \hline 1 & 26.14 & 22.87 & 50.98 & 0.00 & 0.00 & 0.00 \\
2 & 25.65 & 22.44 & 49.98 & 0.01 & 0.80 & 0.56 \\
3 & 25.71 & 22.82 & 48.41 & 0.55 & 0.85 & 0.57 \\
4 & 24.99 & 22.18 & 47.08 & 0.62 & 0.83 & 1.38 \\
5 & 23.98 & 21.63 & 46.20 & 1.38 & 0.95 & 2.42 \\
6 & 23.83 & 21.35 & 45.68 & 1.41 & 1.52 & 2.58 \\
\hline \hline
\end{tabular}

According to Table 4, after 6th period, in the distribution, equilibrium was established. In this case, $45.68 \%$ of the changes in Etherum were caused by itself and 23.83\% from BITCOIN, 21.35\% from BT Cash, 1.41\% from Lite Coin, 1.52\% from the QTUM and $2.58 \%$ from Tether. Cryptocurrencies that affect Etherum most except for itself are BITCOIN and BT CASH respectively.

Table 5: Results of Variance Decomposition for Determining the Causes of Changes in Lite Coin

\begin{tabular}{ccccccc}
\hline \hline Period & DLNBIT & DLNBT & DLNETH & DLNLIT & DLNQTM & DLNTET \\
\hline \hline 1 & 26.85 & 10.09 & 21.97 & 41.00 & 0 & 0 \\
2 & 26.74 & 9.89 & 21.83 & 40.18 & 0.10 & 0.37 \\
3 & 26.33 & 11.48 & 20.93 & 39.89 & 0.10 & 0.36 \\
4 & 25.98 & 11.84 & 21.35 & 38.87 & 0.10 & 0.83 \\
5 & 24.72 & 11.79 & 20.33 & 36.42 & 3.52 & 1.88 \\
6 & $\mathbf{2 1 . 8 6}$ & 10.46 & $\mathbf{1 8 . 0 3}$ & $\mathbf{3 2 . 4 6}$ & $\mathbf{1 4 . 1 5}$ & $\mathbf{1 . 8 2}$ \\
7 & 21.79 & 10.76 & 17.98 & 32.29 & 14.06 & 1.83 \\
\hline \hline
\end{tabular}

According to Table 5, after 6th period, in the distribution, equilibrium was established. In this case, $32.46 \%$ of the changes in Lite Coin were caused by itself and $21.86 \%$ from BITCOIN, 10.46\% from BT Cash, $10.46 \%$ from Etherum, $14.15 \%$ from QTUM and $1.82 \%$ from the Tether. Cryptocurrencies that affect Lite Coin most except for itself are BITCOIN, Etherum, BT CASH and QTUM respectively. 
Table 6: Results of Variance Decomposition for Determining the Causes of Changes in QTUM

\begin{tabular}{ccccccc}
\hline \hline Period & DLNBIT & DLNBT & DLNETH & DLNLIT & DLNQTM & DLNTET \\
\hline \hline 1 & 24.82 & 17.81 & 16.98 & 0.98 & 39.25 & 0 \\
2 & 24.85 & 18.12 & 17.09 & 0.98 & 38.63 & 0.01 \\
3 & 23.86 & 20.34 & 16.10 & 1.55 & 37.29 & 0.02 \\
4 & 23.45 & 20.17 & 15.83 & 1.79 & 36.64 & 0.49 \\
$\mathbf{5}$ & $\mathbf{2 2 . 9 1}$ & $\mathbf{2 0 . 1 1}$ & $\mathbf{1 5 . 4 4}$ & $\mathbf{2 . 0 2}$ & $\mathbf{3 5 . 5 6}$ & $\mathbf{1 . 4 1}$ \\
6 & 22.84 & 19.99 & 15.44 & 2.00 & 35.73 & 1.40 \\
\hline \hline
\end{tabular}

According to Table 6, after 5th period, in the distribution, equilibrium was established. In this case, $35.56 \%$ of the changes in QTUM were caused by itself and 22.91\% from BITCOIN, 20.11\% from BT Cash, 15.44\% from Etherum, 2.01\% from Lite Coin and1.41\% from the Tether. Cryptocurrencies that affect Qtum most except for itself are BITCOIN, BT CASH and Etherum respectively.

Table 7: Results of Variance Decomposition for Determining the Causes of Changes in Tether

\begin{tabular}{ccccccc}
\hline \hline Period & DLNBIT & DLNBT & DLNETH & DLNLIT & DLNQTM & DLNTET \\
\hline \hline 1 & 1.41 & 1.20 & 0.18 & 0.80 & 1.91 & 94.47 \\
2 & 1.30 & 1.09 & 0.20 & 0.76 & 2.70 & 93.40 \\
3 & 1.56 & 2.67 & 0.20 & 0.75 & 2.65 & 91.62 \\
4 & 1.67 & 2.60 & 0.22 & 1.65 & 3.22 & 89.96 \\
5 & 2.06 & 2.56 & 0.67 & 1.99 & 3.18 & 88.79 \\
6 & 2.08 & 3.42 & 0.66 & 1.97 & 3.95 & 87.18 \\
7 & $\mathbf{2 . 0 7}$ & $\mathbf{3 . 6 4}$ & $\mathbf{0 . 7 3}$ & $\mathbf{2 . 2 4}$ & $\mathbf{3 . 9 4}$ & $\mathbf{8 6 . 5 7}$ \\
8 & 2.09 & 3.66 & 0.83 & 2.25 & 3.93 & 86.37 \\
\hline \hline
\end{tabular}

According to Table 7, after 7th period, in the distribution, equilibrium was established. In this case, $86.57 \%$ of the changes in Tether were caused by itself and 2.07\% from BITCOIN, 3.94\% from QTUM, 3.64\% from BT Cash. Cryptocurrencies that affect Tether most except for itself are BITCOIN, QTUM and BT CASH respectively.

\section{CAUSALITY TEST}

The presence and direction of interaction between the series can be investigated by Granger (1969) causality test. The theoretical framework of this test is based on Granger's (1969) article, but it is constantly updated and developed and such it has been made more powerful and robust (Göçer, 2016: 271). For two variables such as Y and X, Granger (1969) causality test can be performed with the help of the following models (Gujarati ve Porter, 2012: 787):

$$
\begin{aligned}
& X_{t}=\beta_{0}+\sum_{i=1}^{q} \delta_{i} X_{t-i}+\sum_{i=1}^{q} \theta_{i} Y_{t-i}+u_{t} \\
& Y_{t}=\alpha_{0}+\sum_{i=1}^{q} \vartheta_{i} Y_{t-i}+\sum_{i=1}^{q} \varphi_{i} X_{t-i}+v_{t}
\end{aligned}
$$

Test hypotheses:

$$
\begin{array}{ll}
H_{0}: \theta_{i}=0 & Y, X^{\prime} \text { in there is no causality. } \\
H_{1}: \theta_{i} \neq 0 & Y, X^{\prime} \text { in causality exists }
\end{array}
$$

Granger (1969) test tries to find out whether the historical values of the $Y$ affect the current period value of $Y$ by looking at whether the $\theta_{i}$ are equal to zero in Equation (3).

If the hypothesis $\mathrm{HO}$ is rejected, it can be said that there is a causal relationship from $\mathrm{Y}$ to $\mathrm{X}$ (Tarl, 2012: 436-443). In this study, Granger causality test was made by taking the first difference of the series and 5 was used as the optimum lag length at this stage determined in VAR analysis. The results are presented in Table 8. 
Table 8: Granger Causality Test Results

\begin{tabular}{|l|c|c|}
\hline The Direction of Causality Relationship & F statistics & Probability Value \\
\hline BT CASH $\rightarrow$ BITCOIN & $2.80^{* *}$ & 0.01 \\
\hline Etherum $\rightarrow$ BITCOIN & $3.80^{* * *}$ & 0.00 \\
\hline Lite Coin $\rightarrow$ BITCOIN & $6.00^{* * *}$ & 0.00 \\
\hline QTUM $\rightarrow$ BITCOIN & $4.33^{* * *}$ & 0.00 \\
\hline BT CASH $\rightarrow$ Lite Coin & $2.96^{* *}$ & 0.01 \\
\hline Tether $\rightarrow$ BT CASH & $2.17^{*}$ & 0.05 \\
\hline Tether $\rightarrow$ Etherum & $1.97^{*}$ & 0.08 \\
\hline QTUM $\rightarrow$ Lite Coin & $8.29^{* * *}$ & 0.00 \\
\hline
\end{tabular}

Note: ${ }^{*} * *$ and $* * *$ show that there is a causality relationship from the first variable to the second variable at the significance level of $10 \%, 5 \%$ and $1 \%$ respectively.

According to the results in Table 8, one-way causality relationships were determined from BT CASH, Etherum, Lite Coin and QTUM to BITCOIN. No causal relationship has been determined from the price of BITCOIN to the value of other crypto coins. One-way causality relationship is determined from the price of QTUM to BITCOIN and Lite Coin. However, no causality relationship was found between the other variables towards the price of QTUM. Similarly, a one-way causality relationship was detected from the price of Tether to the price of BT CASH and Etherum, but no causality relationship was found from the price of the other variables to the price of Tether.

\section{CONCLUSION AND RECOMMENDATIONS}

In this study, the interaction between the closing prices of the cryptocurrencies was analyzed using the daily data of 27.10.2017-25.0.2019 period. Since the data were daily and closely interrelated, simultaneous analysis methods such as the VAR method and Granger causality test were used.

The series were examined by ADF and PP unit root tests and it was observed that all series were I(1) except for Tether. Since VAR analysis and Granger causality tests can be performed only via the stationary series then all series were analyzed by taking their first differences. According to the Impact-Response functions based on the VAR analysis, it can be said that Tether is moving towards becoming an alternative investment tool for all the crypto moneys. Other crypto coins tend to move in the same direction. According to the results of VAR analysis based on Variance Decomposition, BITCOIN, BT CASH and Tether are largely external variables and their prices are not significantly affected by other crypto currencies. In contrast, the values of Etherum, Lite Coin and QTUM are significantly affected by the changes in the values of other crypto coins.

The causality relations between the series were examined by Granger (1969) method. One-way causality relationships were determined from the price of BT CASH, Etherum, Lite Coin and QTUM to BITCOIN, but no causality relationship was found from the price of BITCOIN to the value of other crypto currencies. One-way causality relationships were determined from the price of QTUM to BITCOIN and Lite Coin, while there was no causality from the other variables to the price of QTUM. Similarly, one-way causality relationships were determined from Tether's price to the price of BT CASH and Etherum, no causality relationship can be seen from other variables towards the price of Tether.

\section{REFERENCES}

Arltova, M., Fedorová, D. (2016). Selection of unit root test on the basis of length of the time series and value of AR(1) parameter. Statistika, 96(3), 47-64.

Cocco, L., Concas, G., Marchesi, M. (2017). Using an artificial financial market for studying a cryptocurrency market. 12(2), 345-365.

Cochrane, J. H. (1991). A critique of the application of unit root tests. Journal of Economic Dynamics and Control, 15, $275-284$.

Dikmen, N. (2012). Ekonometri temel kavramlar ve uygulamalar. 2. Baskı, Dora Yayınevi, Bursa.

ElBahrawy, A., Alessandretti, L., Kandler, A., Satorras, R. P., Baronchelli, A. (2017). Evolutionary dynamics of the cryptocurrency market. R.Soc.opensci. 4:170623.

Göçer, İ. (2016). Lisans ve lisansüstü için ekonometri. 1. Baskı. İzmir: Lider Yayınları.

Granger, C. W. J. (1969). Investigating causal relations by econometric models and cross spectral methods. Econometrica, 37(3),424-438. 
Gujarati, N. G., Porter, D. C. (2012). Temel ekonometri. Orijinali: 5. Baskı. Çev. Ümit Şenesen ve Gülay Günlük Şenesen, Literatür Yayıncılık, istanbul.

Luther, W. J. (2015). Cryptocurrencies, network effects, and switching costs. Contemporary Economic Policy.34(3),553-571.

Rossi, E. (2011). Impulse response functions. http://economia.unipv.it/pagp/pagine_personali /erossi/dottorato_svar.pdf, [Access Date: 02.03.2019].

Sims, C. A. (1980). Macroeconomics and reality. Econometrica. 48, 1-48.

Tarı, R. (2012). Ekonometri. 8. Baskı. Kocaeli: Umuttepe Yayınları.

Trenca, I., Mutu, S. (2011). Advantages and limitations of VAR models used in managing market risk in banks. Finance - Challenges of the Future, 13, 32-43.

Triacca, U. (2017). Vector autoregressive models. http://www.phdeconomics.sssup.it/ documents/Lesson17.pdf, [Access Date: 02.03.2019]

\section{APPENDIX}

\section{Appendix 1: Optimal Delay Length Determination Results}

VAR Lag Order Selection Criteria

Endogenous variables: DLNBIT DLNBT DLNETH DLNLIT DLNQTM DLNTET

Exogenous variables: $\mathrm{C}$

Date: 03/01/19 Time: 11:44

Sample: 1334

Included observations: 325

\begin{tabular}{ccccccc}
\hline \hline Lag & LogL & LR & FPE & AIC & SC & HQ \\
\hline \hline 0 & 5853.323 & NA & $3.30 \mathrm{e}-26$ & -35.97122 & $-35.87808^{*}$ & $-35.93404^{*}$ \\
1 & 5920.588 & 130.8049 & $3.23 \mathrm{e}-26^{*}$ & $-35.99131^{*}$ & -35.15305 & -35.65676 \\
2 & 5981.355 & 115.1776 & $3.30 \mathrm{e}-26$ & -35.97142 & -34.38803 & -35.33949 \\
3 & 6040.707 & 109.5716 & $3.40 \mathrm{e}-26$ & -35.94281 & -33.61430 & -35.01350 \\
4 & 6106.917 & 118.9748 & $3.36 \mathrm{e}-26$ & -35.95641 & -32.88278 & -34.72972 \\
5 & 6159.995 & $92.76402^{*}$ & $3.62 \mathrm{e}-26$ & -35.88920 & -32.07045 & -34.36513 \\
6 & 6204.740 & 75.99782 & $4.10 \mathrm{e}-26$ & -35.77071 & -31.20683 & -33.94926 \\
7 & 6252.914 & 79.44922 & $4.57 \mathrm{e}-26$ & -35.67331 & -30.36432 & -33.55448 \\
8 & 6301.369 & 77.52818 & $5.11 \mathrm{e}-26$ & -35.57765 & -29.52353 & -33.16144 \\
\hline \hline
\end{tabular}

* indicates lag order selected by the criterion

LR: sequential modified LR test statistic (each test at $5 \%$ level)

FPE: Final prediction error

AIC: Akaike information criterion

SC: Schwarz information criterion

HQ: Hannan-Quinn information criterion

The optimum lag length is 1 according to FPE and AIC in this table. However, when the 1-delayed VAR model was estimated, an autocorrelation problem was detected in the model, and it was taken as an optimal delay length of 5 models determined according to the LR criteria. Autocorrelation test results for the 5-delayed VAR model:

VAR Residual Serial Correlation LM Tests

Date: 03/01/19 Time: 11:50

Sample: 1334

Included observations: 328

Null hypothesis: No serial correlation at lag $\mathrm{h}$ 


\begin{tabular}{ccccccc} 
Lag & LRE* stat & df & Prob. & Rao F-stat & df & Prob. \\
\hline \hline 1 & 72.76184 & 64 & 0.2119 & 1.140601 & $(64,1575.4)$ & 0.2121 \\
2 & 74.69924 & 64 & 0.1696 & 1.171683 & $(64,1575.4)$ & 0.1698 \\
3 & 62.48444 & 64 & 0.5303 & 0.976344 & $(64,1575.4)$ & 0.5306 \\
4 & 71.51107 & 64 & 0.2426 & 1.120554 & $(64,1575.4)$ & 0.2428 \\
5 & 92.24804 & 64 & 0.0119 & 1.454936 & $(64,1575.4)$ & 0.0120 \\
\hline \hline
\end{tabular}

Null hypothesis: No serial correlation at lags 1 to $\mathrm{h}$

\begin{tabular}{ccccccc}
\hline \hline Lag & LRE* stat & df & Prob. & Rao F-stat & df & Prob. \\
\hline \hline 1 & 72.76184 & 64 & 0.2119 & 1.140601 & $(64,1575.4)$ & 0.2121 \\
2 & 152.2228 & 128 & 0.0709 & 1.196820 & $(128,1916.4)$ & 0.0714 \\
3 & 217.3174 & 192 & 0.1015 & 1.138667 & $(192,1965.9)$ & 0.1029 \\
4 & 286.5945 & 256 & 0.0916 & 1.127037 & $(256,1946.0)$ & 0.0942 \\
5 & 364.0540 & 320 & 0.0452 & 1.148332 & $(320,1903.3)$ & 0.0479 \\
\hline \hline
\end{tabular}

*Edgeworth expansion corrected likelihood ratio statistic.

According to this table, there is no autocorrelation problem in the 5 - delayed VAR model. The graphic of inverse characteristic roots shows that the 5 - delayed VAR model is stable as follows :

\section{Inverse Roots of AR Characteristic Polynomial}

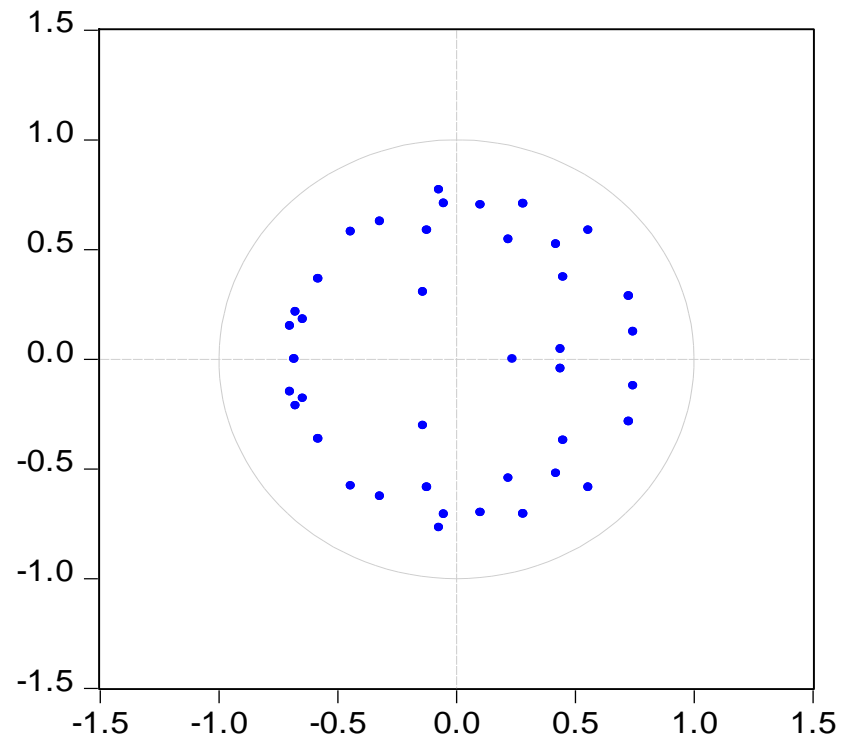

In this graph, it was decided that the 5 delayed VAR model was stable because the inverse characteristic polynomial roots remained within the unit circle. 